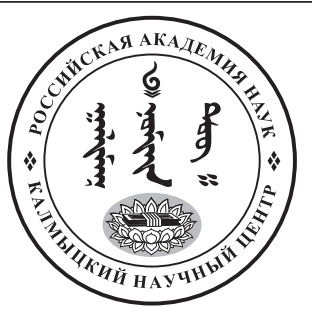

Published in the Russian Federation

Oriental Studies (Previous Name: Bulletin of the Kalmyk Institute

for Humanities of the Russian Academy of Sciences)

Has been issued as a journal since 2008

ISSN: 2619-0990; E-ISSN: 2619-1008

Vol. 13, Is. 4, pp. 961-975, 2020

DOI: 10.22162/2619-0990-2020-50-4-961-975

Journal homepage: https://kigiran.elpub.ru

УДК $398.54 ; 39: 930.2$

DOI: 10.22162/2619-0990-2020-50-4-961-975

\title{
К вопросу о традиционных путешествиях и дорожной культуре башкир
}

\section{Эльза Венеровна Мигранова ${ }^{1}$, Лейсан Хакимьяновна Шангараева ${ }^{2}$}

${ }^{1}$ Институт истории, языка и литературы Уфимского федерального исследовательского центра РАН (д. 71, Проспект Октября, 450054 Уфа, Российская Федерация) кандидат исторических наук, старший научный сотрудник

(iD) 0000-0001-8227-2357. E-mail: mig.el@mail.ru

${ }^{2}$ Институт истории, языка и литературы Уфимского федерального исследовательского центра РАН (д. 71, Проспект Октября, 450054 Уфа, Российская Федерация)

соискатель

(iD) 0000-0002-8328-8382. E-mail: all.lejsan@yandex.ru

(C) КалмНЦ РАН, 2020

(C) Мигранова Э. В., Шангараева Л. Х., 2020

Аннотация. Введение. Правила дорожной культуры, выработанные на протяжении веков, издавна занимали важное место в традиционном мировоззрении и быту башкир. Актуальность. Феномен дорожной культуры и путешествия у башкир до настоящего времени изучен еще недостаточно, и данная статья призвана в какой-то мере устранить существующий пробел и ввести в научный оборот новые данные. Целью данной статьи является систематизация материалов, относящихся к традиционной дорожной культуре башкир, а также рассмотрение ее функциональных и семиотических составляющих, способствовавших преодолению препятствий, с которыми были сопряжены путешествия. Материалы, источники и методы исследования. Основными источниками при подготовке статьи выступили сообщения, материалы участников академических экспедиций XVIII в. - И. И. Лепехина, П. С. Палласа и др.; более поздние этнографические работы; сведения, содержащиеся в башкирском фольклоре, а также полевые материалы, собранные в последние годы в различных районах Республики Башкортостан в ходе этнографических экспедиций. Основными методами, использованными в работе, являются сравнительно-исторический и ретроспективный, с помощью которых выявляется общее и особенное в дорожной культуре башкир и других народов, прослеживается эволюция, определяются тенденции развития изучаемых явлений и т. д. Хронологические рамки исследования: преимущественно укладываются в XVIII - начало XX в. Результаты. Исследование показало, что передвижение в пространстве - путешествие у башкир имело не только практическую, но и метафизическую сторону, поскольку путешественник, по поверьям, одновременно находит- 
ся и в реальном, и в потустороннем мире. Его безопасность зависела как от физических, так и магических действий, а также от расположения духов или «хозяев» различных природных объектов. В традиционном башкирском обществе издавна выработалась своеобразная дорожная культура, целью которой было противостояние различным угрозам, подстерегающим в пути и дорожной нестабильности. Раньше отправление в дорогу чаще являлось уделом мужчин (охота, военная служба, промысел, учеба, торговые поездки, паломничество-хадж и пр.). В статье рассмотрены правила сборов в дорогу; проводы отъезжающего; обычаи, которые следовало соблюдать в дороге, ритуалы, связанные с возращением путника и т. д. Bblводыl. Дорожная культура - это комплекс материальных, духовных составляющих жизни этноса, связанных с путешествием. Башкиры являлись полукочевым народом (постепенно перешедшим к оседлости) с большим стремлением к путешествиям, походам при устойчивом чувстве дома, родной земли.

Ключевые слова: башкиры, дорожная культура, путешествие, дорога, путник, обряды, ритуалы.

Благодарность. Исследование проведено в рамках государственной субсидии проект «Духовная культура тюркских народов Южного Урала» (номер госрегистрации: AAAA-A17-117040350082-3).

Для цитирования: Мигранова Э. В., Шангараева Л. Х. К вопросу о традиционных путешествиях и дорожной культуре башкир // Oriental Studies. 2020. T. 13. № 4. С. 961-975. DOI: 10.22162/2619-0990-2020-50-4-961-975

UDC $398.54 ; 39: 930.2$

DOI: $10.22162 / 2619-0990-2020-50-4-961-975$

\title{
Revisiting Traditional Travel and Road Culture of the Bashkirs
}

\author{
Elza V. Migranova ${ }^{1}$, Leisan Kh. Shangaraeva
}

${ }^{1}$ Institute of History, Language and Literature of the Ufa Federal Research Centre of the RAS (71, Oktyabrya Ave., Ufa 450054, Russian Federation)

Cand. Sc. (History), Senior Research Associate

iD 0000-0001-8227-2357.E-mail: mig.el@mail.ru

${ }^{2}$ Institute of History, Language and Literature of the Ufa Federal Research Centre of the RAS (71, Oktyabrya Ave., Ufa 450054, Russian Federation)

External Postgraduate Student

(iD) 0000-0002-8328-8382. E-mail: all.lejsan@yandex.ru

(C) KalmSC RAS, 2020

(C) Migranova E. V., Shangaraeva L. Kh., 2020

\begin{abstract}
Introduction. The rules of road culture developed over centuries have always occupied an important place in the traditional worldview and everyday life of Bashkirs. The phenomenon of road culture and travel among Bashkirs has remained understudied, and this article serves to eliminate the existing gap to some extent and introduce new data into scientific discourse. Goals. The paper seeks to systematize materials dealing with the Bashkir traditional road culture and consider its functional / semiotic components believed instrumental in overcoming travel-related obstacles. Materials and Methods. The study focuses on reports and materials by participants of $18^{\text {th }}$-century academic expeditions (I. I. Lepekhin, P. S. Pallas, etc.), subsequent ethnographic works, Bashkir folklore narratives, and recent field materials collected in various regions of Bashkortostan. Chronologically, the study covers the period between the $18^{\text {th }}$ and early $20^{\text {th }}$ centuries. Results. The paper shows that movement through space — travel — among the Bashkirs had not only practical but also metaphysical properties, since the traveler is believed to be simultaneously advancing both across the real and
\end{abstract}


the other worlds. So, security is suggested to depend on both physical and magical actions, as well as sympathies of spirits or 'masters' of various natural objects. The traditional Bashkir society has developed a specific road culture that aimed to resist, avert diverse threats. In olden days, travels were seen as a male domain (hunting, military service, fishing, study, trade trips, pilgrimages, etc.). The article discusses the traditional pre-travel and farewell practices, customs that were to be observed en route, rituals supposed to guarantee a traveler's return, etc. Conclusions. The Bashkir road culture is a complex, open, and evolving system. 'Path' and 'road' in traditional representations of Bashkirs were essentially sacral symbols.

Keywords: Bashkirs, road culture, travel, road, traveler, ceremonies, rituals

Acknowlegdements. The reported study was funded by government subsidy — project name 'Turkic Peoples of the Southern Urals: Spiritual Culture' (state reg. no. AAAA-A17-117040350082-3).

For citation: Migranova E. V., Shangaraeva L. Kh. Revisiting Traditional Travel and Road Culture of the Bashkirs. Oriental Studies. 2020. Vol. 13(4): 961-975. (In Russ.). DOI: 10.22162/2619-09902020-50-4-961-975

\section{Введение}

Тема традиционных путешествий и дорожной культуры - достаточно новое, развивающееся направление в российской науке. Основоположниками исследований по данной теме являются: Т. Б. Щепанская, которая на материалах русского населения отобразила общие принципы организации дорожных взаимодействий, уделив значительное внимание ритуально-мифологическому подтексту [Щепанская 2003]; А. В. Головнев - автор концепции антропологии движения, предложивший новый взгляд на сценарии развития культур и народов Евразии [Головнев 2009; Головнев 2018]; А. В. Матвеев сопоставил традиционные культуры путешествия русских, сибирских татар, казахов Среднего Прииртышья [Матвеев 2012].

Исследования М. И. Васильева посвящены сухопутным коммуникациям и скользящему транспорту у русских [Васильев 2009], В. А. Коршункова - дорожным традициям России [Коршунков 2015]. Изучение традиционной культуры путешествия у тундровых ненцев проводится в работе В. Н. Адаева и Р. Х. Рахимова [Адаев, Рахимов 2015]; традиционная дорожная культура карел исследована Г. В. Ивановой [Иванова 2017].

Феномен дорожной культуры и путешествия у башкир до настоящего времени изучен недостаточно. Среди исследователей, занимавшихся данной темой, отметим башкирского этнографа М. Г. Муллагулова - его монография посвящена генезису и истории развития башкирского народного транспорта [Муллагулов 1992].

Труды М. И. Роднова, 3. Г. Аминева, А. Д. Таирова, Г. Н. Гарустовича, Б. А. Азнабаева и др. посвящены разным аспектам истории сухопутных путей сообщения, существовавших на территории Исторического Башкортостана ${ }^{1}$ с древнейших времен [Роднов 2002; Аминев 2009; Таиров 1995; Гарустович 2012; Азнабаев 2016].

Целью данной статьи являются систематизация материалов, относящихся к традиционной дорожной культуре башкир, а также рассмотрение ее функциональных и семиотических составляющих, способствовавших преодолению препятствий, с которыми были сопряжены путешествия.

Формирование башкирского этноса происходило на территории Южного Урала, который по справедливости назвали «плавильным котлом» народов. В сложном многокомпонентном этногенезе башкир участвовали тюркские, монгольские, угорские, финно-язычные племена и народы, а также в ранний период ирано-язычные кочевники. Все это отразилось в культуре, языке, менталитете, физической антропологии и других областях жизнедеятельности башкирского народа, в том числе в дорожной культуре.

Полукочевые башкиры южных, юго-восточных районов преимущественно путеше-

1 Термин, применяемый в исторических, этнографических, лингвистических и других исследованиях для обозначения территории, на которой в различные периоды истории расселялись башкирские племена и башкирский этнос. 
ствовали и передвигались верхом, даже на небольшие расстояния. Башкиры западных, северных районов, раньше перешедшие к оседлости, предпочитали использовать тарантасы, телеги, а на близкие расстояния отправлялись пешком. В дорожной культуре горно-лесных, восточно-зауральских башкир долгое время сохранялись таежные традиции путешествия (зимой на лыжах, подбитых шкурой животных; использование дорожного инвентаря, сходного с алтайскими, южно-сибирскими народами) [Руденко 2006].

В целом указанные различия в формировании традиционной дорожной культуры у разных племенных групп башкир, не исключают того, что башкирский народ формировался на общей территории, под общим названием и имеет сильную привязанность к Южному Уралу как к своей исторической родине.

\section{Дорога и путешествия в традицион- ной культуре башкир}

«Путь», «дорога» в традиционных представлениях башкир являлись сакрально значимыми пространственными измерениями. Расстояния часто измеряются взглядом «что глазом окинешь» или слитного «времени-пространства» - «сколько обойдешь в день» [Толстой 1979: 156-157].

У башкир понятиям «путь», «дорога» соответствует слово юл. От него в башкирском языке образовано множество других слов, связанных с дорожной культурой, путешествием. Словом сәфәр обычно обозначается «поездка», «путешествие с какой-либо целью». Термин сәйәхәт чаще применяется для понятия «путешествие как странствие». Как «путешествие-странствие», «паломничество» понимается и слово гизеу. Для обозначения недальних походов / поездок чаще применяются термины cblzbly 'выход', баpbly, бapbln kaümbly 'сходить и вернуться' и

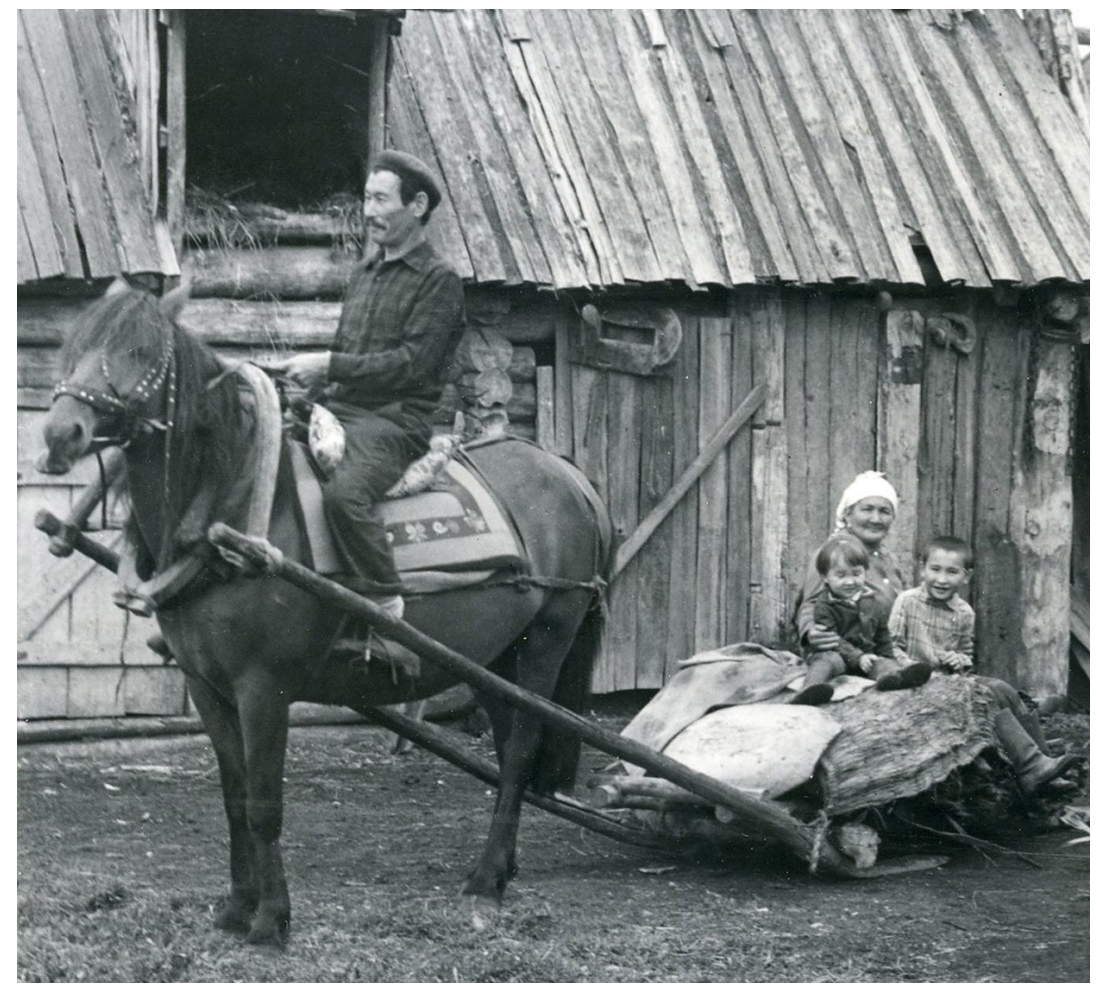

Фото 1. Семья башкир перед отправлением в дорогу. 1977 г., дер. Нукатово Белорецкого района БАССР. Фотограф - М. Г. Муллагулов [ФОЭ ИИЯЛ УФИЦ РАН]. Публикуется с разрешения ИИЯЛ УФИЦ РАН

[Photo 1. Bashkir family before departure. Nukatovo, Beloretsky District, Bashkir ASSR. 1977. Photo by M. Mullagulov [Ufa Federal Research Centre of the RAS; Institute of History, Language and Literature; Photograph Collection]. Courtesy of the Institute of History, Language and Literature (Ufa Federal Research Centre of the RAS)] 


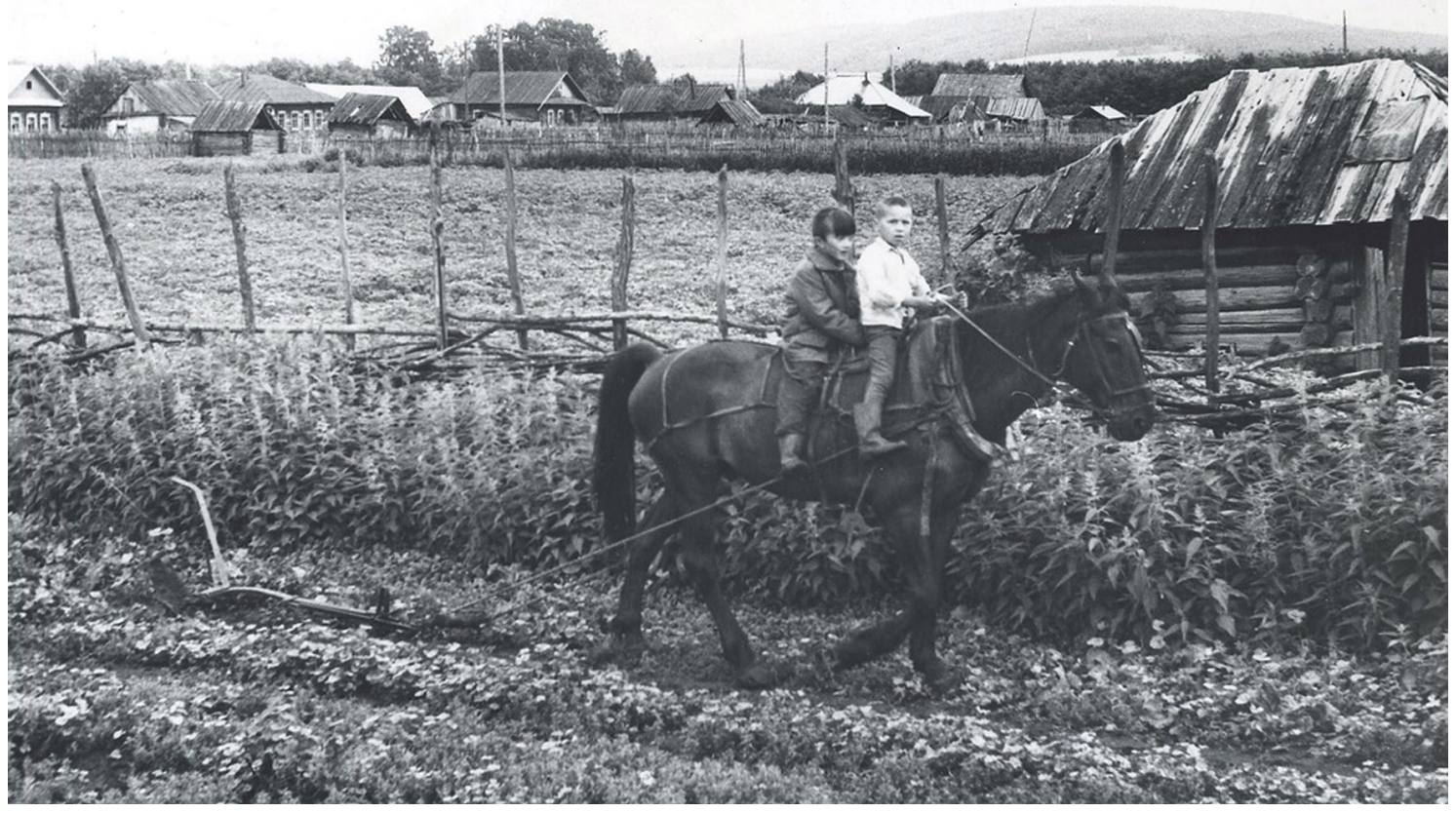

Фото 2. Дети верхом на лошади. 1977 г., дер. Ст. Халилово Дуванского района БАССР. Фотограф С. Н. Шитова [ФОЭ ИИЯЛ УФИЦ РАН]. Публикуется с разрешения ИИЯЛ УФИЦ РАН

[Photo 2. Children riding a horse. Khalilovo, Duvansky District, Bashkir ASSR. 1977. Photo by S. Shitova [Ufa Federal Research Centre of the RAS; Institute of History, Language and Literature; Photograph Collection]. Courtesy of the Institute of History, Language and Literature (Ufa Federal Research Centre of the RAS)]

т. д. Развитая терминология дорожной культуры может косвенно свидетельствовать о важности дорожной культуры в системе жизнеобеспечения башкир с давних времен.

Природно-географическое разнообразие Исторического Башкортостана способствовало сложению у различных родоплеменных групп башкир территориальных особенностей в хозяйстве, культуре и быту. Издавна их природные (пещеры, горы, реки, озера, леса и др.) и некоторые культурные (дороги, отдельные поселения, могилы святых и т. д.) объекты были не только сакрализованы, но и в некотором роде структурированы, маркированы, особенно в пределах родовых земель. В качестве доказательства древности проживания башкир на своих землях, П. С. Паллас приводит тот факт, что «множество прилагательных речей, коими башкирцы большие и малые горы, все ручьи и малейшие притоки, долины, частые рощицы и все прочие урочища отмечают» [Паллас 1786: 66].

В южных и юго-восточных частях республики долгое время сохранялся относи- тельно однородный этнический состав населения, а основой хозяйства башкир вплоть до начала XX в. оставалось скотоводство, предполагавшее в теплое время года откочевку со стадами на родовые пастбища йайләү. Это событие было, конечно, с одной стороны, путешествием, и довольно далеким (расстояния перекочевок порой измерялись десятками километров), но не воспринималось как путь в неизвестное, поскольку маршруты выездов к летовкам, как правило, повторялись из года в год.

Войлочная юрта (кош) - летнее жилище башкира была тем же родным домом, с которым он в случае необходимости мог отправиться в дорогу. В северных же, западных и отчасти северо-восточных районах республики в комплексе хозяйственных занятий башкир уже, по крайней мере, с конца XVII в., наряду со скотоводством, заметную роль играло земледелие, население многих деревень являлось оседлым. Однако, даже несмотря на ограничение дальности перекочевок и даже отказ от кочевок, у части оседлого башкирского населения еще ка- 


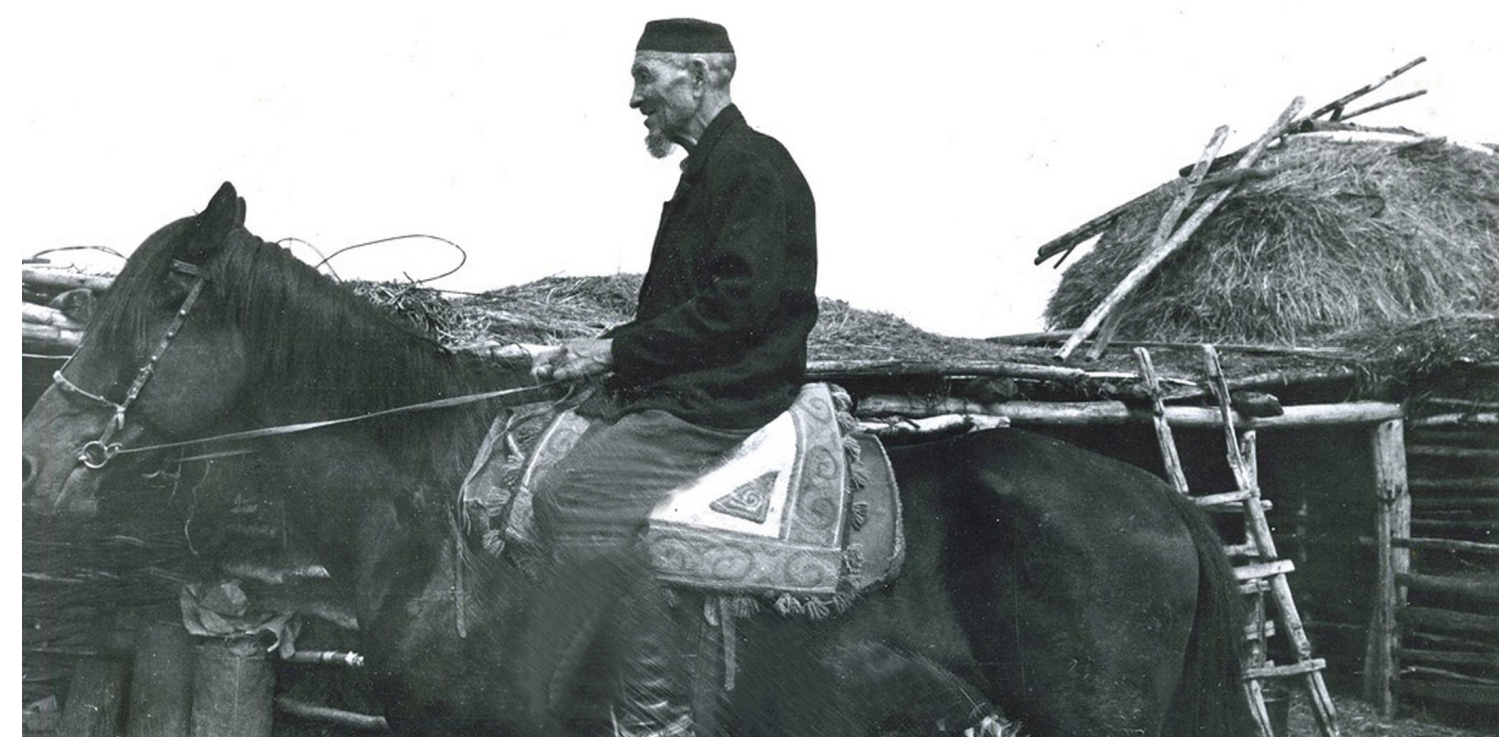

Фото 3. Пожилой башкир перед отправлением в дорогу. 1972 г., дер. Аскарово Альменевского района Курганской области. Фотограф - Р. М. Султанов [ФОЭ ИИЯЛ УФИЦ РАН]. Публикуется с разрешения ИИЯЛ УФИЦ РАН

[Photo 3. Bashkir old man before departure. Askarovo, Almenevsky District, Kurgan Oblast. 1972. Photo by R. Sultanov [Ufa Federal Research Centre of the RAS; Institute of History, Language and Literature; Photograph Collection]. Courtesy of the Institute of History, Language and Literature (Ufa Federal Research Centre of the RAS)]

кое-то время доминировала скотоводческая психология: некоторые «кочуют» у себя на дворе, разбивают «у себя кибитку или ставят лубочный домик, рядом кладут печь с казаном и перебираются ... со всем своим скарбом в новое жилище» [Назаров 1890: 174]. В этих «кочевках», разумеется, уже не было хозяйственной необходимости, но они свидетельствовали о живучести и устойчивости кочевнических традиций.

Космогонические мифы башкир, нашедшие отражение в эпосах «Урал-батыр», «Акбузат», «Заятуляк и Хыухылыу» и др., во многом строятся на основе путешествий героев, в процессе которых они активно занимаются миротворчеством и мироустройством. В качестве главного помощника и верного друга обычно выступает конь, наивысшим воплощением которого является крылатый конь - тулпар Акбузат; спутниками эпических героев также являются собака / волк, бык / корова, олень и т. д. [Башкирские сказки 1996].

В основе одной из версий о происхождения башкирского этнонима лежит предание о нахождении древними башкирами в пути и обретении родины во главе с вожаком то- темом - волком, приведшем их на Урал. Отсюда бaukopm - баш ('голова, глава, ведущий, вождь') и kopm ('волк') [Татищев 1962: 252; Рычков 2002: 33; Георги 1799: $85]$.

И если для мифологических и фольклорных героев путешествие - это обычное дело, то для основной массы населения оно, как правило, ассоциировалось с трудностями, испытаниями, опасностями, вынужденным отлучением из дома. Постепенно в народе вырабатывалась дорожная культура, культура путешествия, закреплялись правила и табу, связанные с ним, создавался противовес дорожным угрозам и путевой нестабильности [Алламуратова 2015: 27-29; Псянчин 2017: 118].

Основополагающее значение концепта путешествия в мировоззрении народа состояло в движении, действии, направленном не столько на получение материального блага, сколько на исследование, получение нового знания, опыта, познания неизвестного: Йөрөгән ил күргән 'Кто ездил по миру, мир познал', Юл китапhыз з а ykыma 'Путь и без книги учит человека' и т. д. [БНТ 1980: 253-260]. 


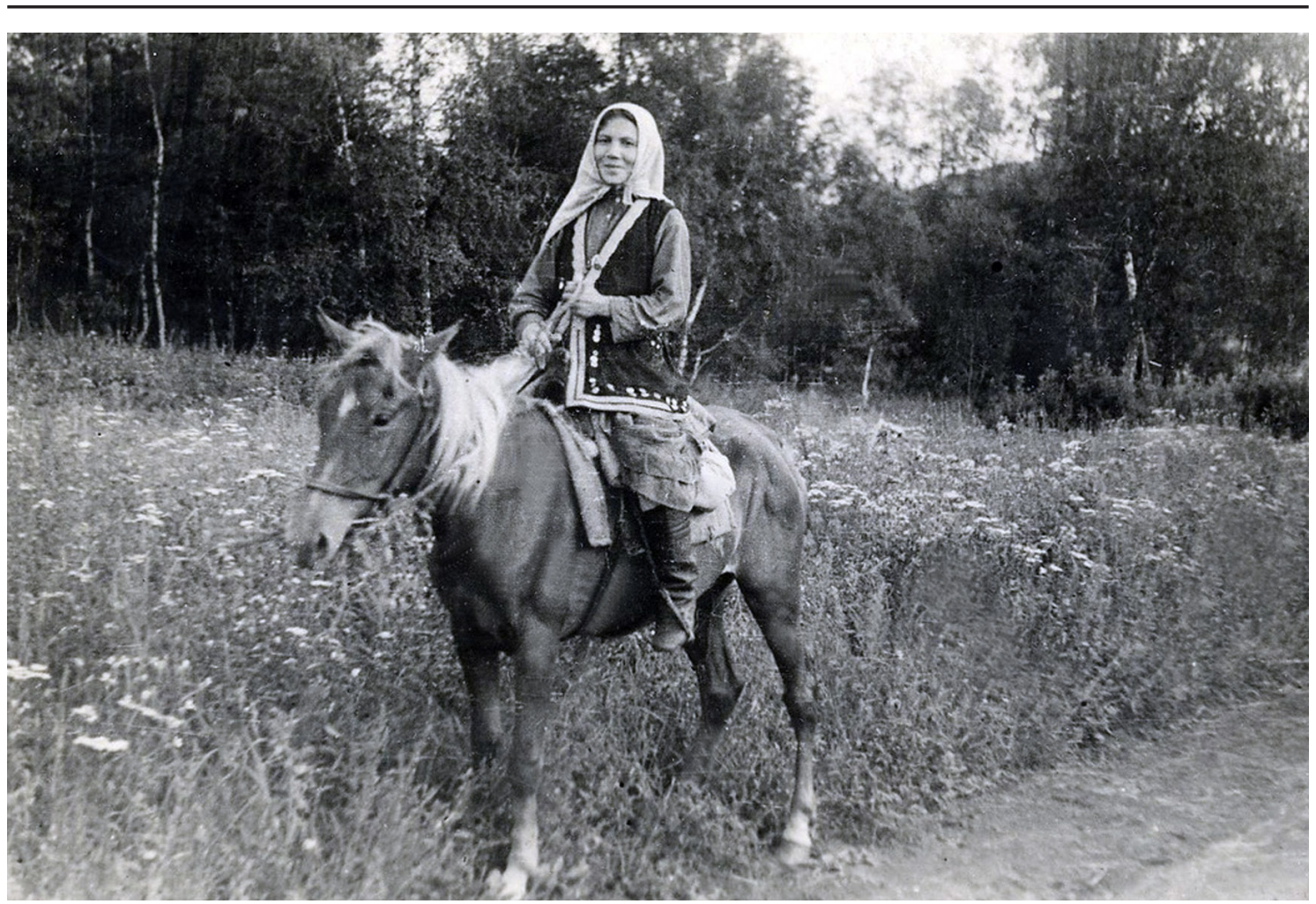

Фото 4. Молодая женщина верхом на лошади. Фото сер. ХХ в. [ФОЭ ИИЯЛ УФИЦ РАН]. Публикуется с разрешения ИИЯЛ УФИЦ РАН

[Photo 4. Young woman riding a horse. Ser.: $20^{\text {th }}$ Century [Ufa Federal Research Centre of the RAS; Institute of History, Language and Literature; Photograph Collection]. Courtesy of the Institute of History, Language and Literature (Ufa Federal Research Centre of the RAS)]

Согласно представлениям башкир, дорога являлась мужским пространством: Ир азывы менән ат азыљlвы - юлда 'Удел мужчины и коня - дорога' [БНТ 1980: 254]. Даже на недальнее расстояние башкиры раньше предпочитали отправляться верхом. По сообщению И. И. Лепехина: «Башкирская привычка и изобилие лошадей сделала их тупоногими, так что Башкирец за важный поход почитает, когда ему должно будет около версты пройти пешком» [Лепехин 1802: 111].

Их уход из дома, как правило, был связан с промыслом, службой; учебой, с торговыми поездками, паломничеством, отъездом на заработки и т. д. Для женщин же в прошлом главным, а, подчас, единственным путешествием в жизни, являлся переезд к мужу после свадьбы, а также гостевые визиты к родственникам. Тем не менее нередкими были случаи, когда башкирки, воспитанные в духе независимости, отваги и преданности вере предков и родному Уралу, являлись великолепными наездницами, и вместе со своими мужьями, отцами, братьями, сражались на поле брани.

\section{Дорожные запреты и предписания}

Характер предстоящего путешествия и его побудительная причина определяли особенности подготовки к нему, а также порядок действий человека, отправляющегося в дорогу. Особыми, магически насыщенными обрядами, сопровождались и отправление в дорогу, и встреча вернувшегося путника. Эти ритуальные действия были призваны защитить путника от опасностей, подстерегавших в дороге, а также избавить от возможных негативных последствий путешествия.

Мероприятия, начинавшиеся в семье за некоторое время до отправления кого-либо из ее членов в путь, условно можно разделить на две группы. К первой относятся действия, направленные на подготовку материальной составляющей путешествия; ко второй - комплекс магических действий для обеспечения удачной дороги. 
Обязательным был осмотр и починка одежды, в которой путешествующий собирался отправиться в путь, причем делалось это заранее, поскольку существовал запрет непосредственно перед дорогой шить, чинить, стирать одежду, мыться, стричь волосы, ногти и т. д. Определенное значение этот обычай имел и в семантическом прочтении - зашивание якобы закрывало предстоящий путь.

Ряд запретов для путника возник у башкир позднее, под влиянием ислама: «Без омовения нельзя выходить на улицу, отправляться в дорогу»; считалось, что под ногами человека, не совершившего омовения, высыхают травы, и путь его становится неблагоприятным [Ғайсина 2010: 91].

Накануне отправления в дорогу, члены семьи отъезжавшего совершали действия, направленные на обеспечение благополучия в пути. У башкир до сих пор существует поверье, что перед выходом в дорогу нельзя оставлять грязную посуду; информанты также сообщали, что все ведра и умывальник следовало наполнить свежей водой [ПМА: 1; ПМА: 2]. Хозяйки загодя наводили порядок в доме, поскольку для оставшихся существовал запрет на какое-то время стирать, убирать золу из печки, мыть полы, посуду и т. д. Нарушение данного запрета могло привести к неудачной дороге, в народе говорили: «Заметешь человеку следы, он и не вернется» [ПМА: 3]. Данное табу действовало, пока те, кто уехал, не доберутся до места или не пересекут какую-либо реку [ПМА: 2; ПМА: 3].

Эти временны́е и пространственные рамки подсказывают нам возможную интерпретацию рассматриваемого запрета. Как известно, жилище - это центральный локус жилищного и ритуального мифологического пространства [Байбурин 1983: 43]. После отъезда родных или гостей любое намеренное изменение этого центрального локуса могло повлечь за собой непредсказуемые изменения и в иных локусах пространства, где в это время могли находиться путешествующие. Метафизическая связь путешествующих с оставленным домом осуществлялась по так называемым невидимым каналам - «следам». Нетронутые «следы» являлись гарантией относительной стабильности реального и мифологическо- го пространства и определенной гарантией возвращения путешествующего домой по ним, особенно в случае опасности. Поэтому стирания, вымывания «следов» старались не допустить. Традиция мытья полов после выноса из дома покойного, видимо, является противоположностью данного поверья.

Мусульмане, собираясь в путь, особенно сопряженный с опасностями, заходили в мечеть с дорожным подаянием - юл хәйере. Его также могли дать сиротам, детям или одиноким старикам. В качестве милостыни выступали деньги, молочные продукты, хлеб, а если человек был совсем беден, то он «мог просто погладить по голове сироту» [ПМА: 3]. По сообщениям информантов, как подаяние осмысливалось и угощение домашних животных - собак, реже кошек или даже птиц - воробьев, голубей, кур [ПМА: 4; ПМА: 2].

Важным этапом подготовки к отправлению в дорогу (особенно дальнюю, длительную) было прощание со своими местными сакральными природными объектами. Так, девушка, выданная замуж, или рекрут (перед отправкой на службу) незадолго до отъезда из отчего дома, поднимались на гору и, прощаясь с родными местами, просили у них благословления. По приезде в селение мужа, невесте предстоял противоположный обряд приветствия святынь своей новой родни: «При входе в юрту своего мужа, молодая делала коленопреклонение замечательным по волости горам, рекам...» [Филоненко 1914: 304].

Для нейтрализации потенциальных дорожных опасностей предпринимались многочисленные символические действия. Так, уходящему давали откусить от свежеиспеченного каравая, которым затем обводили вокруг его пояса и берегли до возвращения, «чтобы пища притягивала» [ПМА: 2; ПМА: 3; ПМА: 5].

У некоторых групп башкир обязательными при проводах в армию были блюда из курицы, что объясняется символическими представлениями, связанными с этой птицей: «Курица назад гребет - солдат должен домой вернуться». Иногда живой курицей обводили вокруг пояса рекрута, а затем ее варили и отдавали ему в дорогу [Тулвинские татары 2004: 156].

У башкир существует обряд, когда уходящего на службу выводили спиной впе- 
ред - ради его успешного возвращения. В особых случаях, например, перед отправлением на войну, в одежду уезжающего вшивали молитвы или кусочек высушенного собственного последа. Кроме этих оберегов, магической защитой могли выступать также нитки, острые металлические предметы, к примеру булавки, закрепленные к одежде, мешочки с солью или родной землей, выписанные на листочек суры из Корана и т. д. [ПМА: 3].

\section{Дорожная провизия}

Из еды и питья в дорогу обычно брали непортящиеся продукты: сушеное мясо, творожный сыр - курут, хлеб, лепешки или сухари, соль, кумыс [Мигранова 2016; Мигранова 2018]. «Копченая конина и курут, который, будучи засушон, может сохраняться более года без всякаго повреждения и служит заменою хлебу» [Казанцев 1866: 29]. «Каждый башкирец, отправляясь из места своего жительства куда-нибудь на недальнее расстояние, непременно берет с собою небольшой кожаный мех (турсук), наполненный кумысом, который в дороге составляет для него и пищу, и питье» [P-H 1832: 269].

Удобным в плане перевозки и питания в дороге было и толокно из предварительно обжаренных и размолотых зерен пшеницы. Нередко путешественников сама природа спасала от голода: «Однажды вышел Хаубан в поле. Шел он и радовался... дикому луку и кислому щавелю — как праздничному угощению» [БНТ 1987: 135].

Другой парень, «пробираясь через непролазную чащу леса, питался этлеком², саранкой и всякими прочими ягодами» [Башкирские сказки 1996: 70, 141]; часто путники, чтобы прокормиться в дальней дороге или походе, промышляли охотой.

Вообще, отправление на охоту было одним из основных традиционных видов путешествий у башкир. Охотниками становились либо вынужденно, чтобы прокормиться, либо передавали этот навык по наследству от отца к сыну, либо охота являлась развлечением для богатых. По поверью, на охоту отправлялись молча, чтобы не спугнуть диких животных. Существовала примета, запрещавшая женщинам не только

${ }^{2}$ Бубенчик лилиелистный, латинское название - Adenophora liliifólia. охотиться, но даже провожать мужчин на этот промысел [ПМА: 4].

Торговые поездки и названия традиционных дорог

Торговые поездки были, конечно, не столь рискованны, как военный поход или охота на медведя, но все равно таили множество неожиданностей, трудностей и опасностей, особенно в период сложения торговых путей. Угроза исходила как от природных явлений, так и от грабителей. Торговали, главным образом, на местных ярмарках, а также на Мензелинской и Бугульминской, некоторые купцы ездили на Ирбитскую, Макарьевскую и другие ярмарки. Заключались торговые сделки со среднеазиатскими и казанскими купцами. В исторических источниках в числе торговых городов упоминаются Уфа и Оренбург [Пекарский 1872; Рычков 2002].

По территории Башкортостана с древности проходили караванные пути; наиболее известные из них — «Великий шелковый путь» и «Великий меховой путь», связывавшие Европу и Азию. На протяжении этих дорог возникали и места остановок для отдыха, часто они устраивались неподалеку от водных объектов и становились традиционными. До настоящего времени на Южном Урале сохранилась одна из северных ветвей «Великого шелкового пути», идущего, в том числе, по горам и возвышенностям Башкортостана и уходящего в Казахстан и Среднюю Азию под названием Кәнифә юль 'Дорога Канифы'. Название дороги связано с легендой о башкирской девушке по имени Канифа, бежавшей из казахского плена [Аминев 2009: 27].

Известна также древняя дорога Кунъыр буга юльл 'Дорога бурой коровы', тянущаяся с юга на север по отрогам Уральского хребта. Эти дороги на всем своем протяжении не имеют водных преград, поэтому были удобны для перемещения.

Наряду с транзитными, существовали и местные направления, проходившие по территориям башкирских племен и родов, местам их кочевок.

C середины XVII в. почти все караванные пути в Средней Азии были взяты под контроль калмыками. Столкновения между башкирами и калмыками часто вынуждали среднеазиатских купцов пересекать русскую границу за Уралом [Азнабаев 2016: 106]. 


\section{Дорожные приметы}

Выход из родного дома расценивался как выход из организованного, структурированного пространства, поэтому важно было правильно преодолеть именно этот первый рубеж. Перед отправлением в дорогу, необходимо было присесть «на дорожку». Прощались словами: Хуш! hay бульвыз’! Юлдарывыз еңеел булһын! 'До свидания! Пусть ваши дороги будут легкими!'.

Первой границей, которую переходил путешествовавший, уходя из «своего» пространства в «чужое», являлся порог дома, переступать который следовало с правой ноги. После выхода из дома возвращаться, например за забытой вещью, было уже нежелательно. Этот запрет и в настоящее время распространен повсеместно. Если необходимо было все же вернуться, надо было посмотреться в зеркало [ПМА: 1; ПМА: 2].

Дождь считался хорошей приметой и сулил удачу в пути, добрым предзнаменованием была и встреча с другим путником. Неудачей могла обернуться встреча с похоронной процессией, женщиной с пустыми ведрами, змеей, безрогой коровой, черной кошкой и т. д. [ПМА: 1; ПМА: 3; ПМА: 4].

По поверьям, на территории населенных пунктов или вне их, имелись места, где мог произойти контакт человека с иным миром. При приближении к таким местам и при их пересечении, путешествующие должны были соблюдать определенные меры безопасности. По представлениям башкир, одним из таких мест был перекресток - место концентрации злых духов, здесь ничего нельзя было поднимать с земли. Мост также считался опасным местом, из-под него могло неожиданно выскочить демоническое существо. Путешественники также старались не проходить под столбами или арками, стоящими треугольником, а обходили или объезжали их [ПМА: 1; ПМА: 5].

Важной границей являлся последний перекресток, до которого домашние часто провожали путников: здесь уходящий уже окончательно приобретал статус путника. Кроме перекрестка, расставание могло происходить и в других точках пространства у ближайшего родового леса, реки, подножья горы и т. д. Уходящему не рекомендовалось оборачиваться, особо этот запрет подчеркивается в свадебных и рекрутских обрядах.
По представлениям башкир, мир был заполнен многочисленными природными препятствиями - лесами, реками, горами, болотами и пр., которые традиционная культура населяла «хозяевами» — различными добрыми, нейтральными или злыми духами. Возможность продолжать движение, а иногда и жизнь путешествующего зависели от благорасположения этих существ, их задабривали, оставляя монеты, ленточки, кусочки пищи и говорили: Мине тотма, ошоно тот 'Меня не трогай, возьми вот это' [ПМА: 2].

В случае ночевки в лесу заранее готовили место, строили шалаш, очерчивали вокруг себя острым металлическим предметом круг, читая при этом молитвы, и клали около себя предметы конской упряжи, поскольку конь часто выступал в роли сверхъестественного покровителя, тотема или защитника. Защитой от нечистой силы, по поверьям, могла выступить молитва или выстрел из ружья (по представлениям башкир порох имел охранительную силу). По сведениям информантов, избавиться от злых духов, можно было, громко забранившись, причем, считалось, что наибольшим эффектом обладали русские нецензурные ругательства [ПМА: 3].

\section{Возвращение}

При возвращении путника домой, границы мифологического пространства пересекались в обратном направлении. Теперь путник уже не уходил в неизвестное, а возвращался из него, до этого в коллективном сознании своих близких считаясь, как бы «не существующим в их мире». По мнению исследователей, это связано с тем, что человек, оставляя свой дом, семью, общину покидал не только зону своего реального жизненного пространства, но и метафизическое пространство и время: «собственно сам выход из своего мира равносилен смерти» [Ахундов 1982: 55].

Поэтому смысл обрядов возвращения заключался в обратной социализации всеобщем узнавании путешественника, вводе его в пространственно-временной континуум дома, семьи, населенного пункта и очищении от влияния хаоса. У ворот дома родные встречали вернувшегося словами: hayмыhыzыз ! Рәхим итегез̧! 'Здравствуйте! Добро пожаловать!'. Если разлука 
была долгой, восклицали: Kapazblз әле кем kaümkaн! Taнылn ma булмай! 'Смотрите, кто приехал! Даже не узнать!'. И приглашали в дом.

Путнику нужно было смыть с себя дорожную пыль, для чего по возможности затапливали баню. Помимо физического очищения тела, мытье в бане имело целью и магическое очищение, характерное для многих переходных обрядов (баня для роженицы и младенца, баня для супружеской пары после первой брачной ночи, знахарское лечение в бане и т. д.). После мытья в бане бывший путешественник надевал свою обычную, узнаваемую в своем мире, домашнюю одежду.

Совершение паломничества, этого долгого, иногда многомесячного, иногда больше года, путешествия, сопряженного с многочисленными опасностями, меняло статус человека в духовном и физическом плане, паломник-хаджа приобретал новые качества. Известна информация, что «побывав в Мекке, мусульмане считали себя очищенными и часто входили в дом не через обычную входную дверь как оскверненную, а через новую, с обратной стороны дома. Когда паломник переступал родной порог, в доме резали жертвенного барашка, устраивали торжественную встречу» [Хабибуллина 2009: 314].

И в других случаях благополучного возвращения путника после дальнего или важного путешествия, в его доме собирались родственники, знакомые, специально оповещенные об этом. Совершалось обещанное заранее жертвоприношение; этим мясом угощали знакомых, соседей, раздавали малоимущим.

\section{Заключение}

Исследование показывает, что дорожная культура башкир - сложная, открытая, развивающаяся система, включающая прохождение и отчасти освоение пространства. В фольклоре, особенно в сказках и эпосе, сохранились наиболее архаичные пласты дорожной культуры башкир и представления народа о путешествиях.

В отличие от истинных номадов, у которых «кочевая траектория распределяет людей (и животных) в открытом пространстве без установленных пределов» [Головнев 2018: 7], у башкир довольно рано сформи- ровалась локальная модель пространства с окультуренным «священным центром мира» - Южным Уралом, отмеченным многочисленными маркерами - топонимами, легендами, преданиями; древними дорогами (Кәнифә юль, Куныл бува юльл и др.) и населенными пунктами (аулами, в которые постепенно превратились зимовки - кышилау), а также весенними, летними, осенними местами родовых кочевий (язлау, йәйләү,

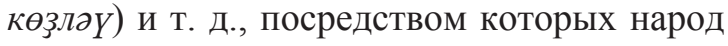
маркировал свою территорию.

Архивными материалами и старинными родословными - шәжәрә - подтверждается наличие у башкир десятков деревень уже в XVII в. Однако полукочевые башкиры, привыкшие находиться в движении (конечно, внутри определенного ареала), довольно часто меняли место жительства (иногда жители переносили аулы на более удобные для зимовки места, иногда причиной переезда был передел вотчинных земель, иногда новые поселения возникали взамен уничтоженных (сожженных) в результате набегов соседей-степняков или карательных операций в ходе подавления народных волнений и т. д.) [Башкиры 2002: 112].

Свойственное бывшим кочевникам легкое отношение к перемене места жительства подметил у башкир в XVIII в. И. Г. Георги: «Ежели им какое-нибудь место в их стране покажется лучше прежнего, то покидают они свою деревню и строят новую» [Георги 1799: 89].

Однако, несмотря на это, башкиры с древности обладали развитым чувством «дома», «исконной родины», имея ввиду главным образом Южный Урал и прилегающие территории. Это чувство являлось одним из определяющих этнических маркеров, способствовавших объединению различных племенных групп башкир в единый народ, родиной которого являлся Исторический Башкортостан. В связи с этим мы можем назвать башкир «движущимся народом с оседлым менталитетом».

Изучение эволюции взглядов башкир на движение в ходе исторического процесса, постепенная смена кочевого мировоззрения на полуоседлое, а затем оседлое, анализ того, как у башкир уживался полукочевой образ жизни и мышления при устойчивом чувстве дома, родной земли, - задача предстоящего серьезного исследования. 
Данную статью авторы рассматривают в значительной мере как постановку проблемы, начальное прикосновение к исследуемой проблеме.

Однако, представленные в данной ра-

\section{Полевые материалы авторов}

ПМА: 1 - Полевые материалы Э. В. Миграновой. Экспедиция в Янаульский район Республики Башкортостан. 2018 г.

ПМА: 2 - Полевые материалы Л. Х. Шангараевой. Экспедиция в Гафурийский район Республики Башкортостан. 2014 г.

ПМА: 3 - Полевые материалы Л. Х. Шангараевой. Экспедиция в Бурзянский, Кугарчинский районы Республики Башкортостан. 2013 г.

ПМА: 4 - Полевые материалы Э. В. Миграновой. Экспедиция в Ишимбайский район Республики Башкортостан. 2019 г

ПМА: 5 - Полевые материалы Л. Х. Шангараевой. Экспедиция в Баймакский район Республики Башкортостан. 2017 г.

\section{Источники и литература}

Адаев, Рахимов 2015 - Адаев B. Н., Рахимов $P$. $X$. Традиционная культура путешествия тундровых ненцев // Вестник археологии, антропологии и этнографии. 2015. № 2 (29). C. 151-158.

Азнабаев 2016 - Азнабаев Б. А. Башкирское общество в XVII - первой трети XVIII вв. Уфа: РИЦ БашГУ, 2016. 370 с.

Алламуратова 2015 - Алламуратова Л. Х. Подготовка к отправлению в путь в традиционной культуре путешествия башкир // Перспективы науки. 2015. № 5(68). С. 27-29.

Аминев 2009 - Аминев 3. Г. Дороги Южного Урала и их роль в этногенезе башкир // Феномен евразийства в материальной и духовной культуре, этнологии и антропологии башкирского народа: мат-лы Всерос. науч.-практ. конф. (г. Уфа, 27-29 мая 2009 г.). Уфа: ИИЯЛ УНЦ РАН, 2009. С. 25-27.

Ахундов 1982 - Ахундов М. Д. Концепции пространства и времени: истоки, эволюция, перспективы. М.: Наука, 1982. 224 с.

Байбурин 1983 - Байбурин А. К. Жилище в обрядах и представлениях восточных славян. Л.: Наука, 1983. 188 с.

Башкирские сказки 1996 - Башкирские сказки и легенды / сост. Ф. А. Надриина. Уфа: Башк. кн. изд-во, 1996. 204 с. боте материалы и сведения могут быть использованы для сравнительно-сопоставительного анализа при проведении этнологических, культурологических и иных исследований.

\section{Authors' Field Data}

Migranova E. V. 2018 Expedition to Yanaulsky District (Republic of Bashkortostan, Russia): Field Notes and Interviews. (In Bash.)

Migranova E. V. 2019 Expedition to Ishimbaysky District (Republic of Bashkortostan, Russia): Field Notes and Interviews. (In Bash.)

Shangaraeva L. Kh. 2013 Expedition to Burzyansky and Kugarchinsky Districts (Republic of Bashkortostan, Russia): Field Notes and Interviews. (In Bash.)

Shangaraeva L. Kh. 2014 Expedition to Gafuriysky District (Republic of Bashkortostan, Russia): Field Notes and Interviews. (In Bash.)

Shangaraeva L. Kh. 2017 Expedition to the Baymaksky District(Republic of Bashkortostan, Russia): Field Notes and Interviews. (In Bash.)

БНТ 1980 - Башкирское народное творчество. Пословицы и поговорки / сост. Ф. А. Надршина. Уфа: Башк. кн. изд-во, 1980. 472 с.

БНТ 1987 - Башкирское народное творчество. Эпос / сост. М. М. Сагитов. Уфа: Башк. кн. изд-во, 1987. 544 с.

Башкиры 2002 - Башкиры. Этническая история и традиционная культура / под ред. Р. М. Юсупова. Уфа: Башкирская энциклопедия, 2002. 248 с.

Васильев 2009 - Васильев М. И. Русские сухопутные коммуникации и скользящий транспорт X - начала XX веков: основные тенденции развития: автореф... дис. д-ра ист. наук. СПб., 2009. 48 с.

Ғайсина 2010 - Ғайсина Ф. Ф. Башкорттарзың юлға бәйле ырым-ышаныузары, тыйыузары (= Башкирские поверья и запреты, связанные с дорогой) // Урал-Алтай: через века в будущее. Вып. 1. Уфа: ИИЯЛ, 2010. С. 89-92.

Гарустович 2012 - Гарустович Г. Н. След великой замятни (Местонахождение XIV века у деревни Брик-Алга). Уфа: Гилем, 2012. $222 \mathrm{c}$.

Георги 1799 - Георги И. Г. Описание всех обитающих в Российском государстве народов: Их житейских обрядов, обыкновений, одежд, жилищ, упражнений, забав, вероисповеданий и прочих достопамятностей. Ч. II. СПб.: Имп. акад. наук, 1799. 178 с. 
Головнев 2009 - Головнев $A$. В. Антропология движения (древности Северной Евразии). Екатеринбург: УрО РАН; Волот, 2009. 496 с

Головнев 2018 - Головнев $A$. В. Концептуализация мобильности в антропологии и этнографии // Уральский исторический вестник. 2018. № 3 (60). C. 6-15.

Иванова 2017 - Иванова Г. В. Традиционная дорожная культура карел на страницах газеты «Олонецкие губернские ведомости» (1838-1917 гг.) // Финно-угорский мир. 2017. № 2. C. 72-84.

Казанцев 1866 - Казанцеев Н. Описание башкирцев. СПб.: Тип. т-ва «Общественная польза», 1866.97 с.

Коршунков 2015 - Коршунков B. A. Дорожная традиция России: поверья, обычаи, обряды. М.: Форум, 2015. 240 с.

Лепехин 1802 - Лепехин И. И. Продолжение дневных записок путешествия академика и медицины доктора Ивана Лепехина в 1770 г. Ч. II. СПб.: Имп. акад. наук, 1802. 338 с.

Матвеев 2012 - Матвеев А. В. Традиционная культура путешествия населения Среднего Прииртышья (XIX - первая треть XX века). Омск: Наука, 2012. 196 с.

Мигранова 2016 - Мигранова Э. В. Башкиры. Традиционная система питания: историко-этнографическое исследование. Уфа: Китап, 2016. 292 с.

Мигранова 2018 - Мигранова Э. В. Реликты традиционных запретов в современном башкирском обществе // Проблемы востоковедения. 2018. № 4 (82). С. 30-37.

Муллагулов 1992 - Муллагулов М. Г. Башкирский народный транспорт. XIX - начало ХХ в. Уфа: БНЦ УрО РАН, 1992. 152 с.

Назаров 1890 - Назаров П. С. К этнографии башкир // Этнографическое обозрение. 1890. Вып. 1-2. С. 164-192.

Паллас 1786 - Паллас П. С. Путешествие по разным провинциям Российской империи. Кн. І. Ч. 2. СПб.: Тип. Имп. акад. наук, 1786. $476 \mathrm{c}$.

Пекарский 1872 - Пекарский П. П. Когда и для чего основаны города Уфа и Самара? (Исторические разыскания академика П. П. Пе-

\section{Sources and References}

Adaev V. N., Rakhimov R. Kh. Traditional travel culture of the tundra Nenets. Vestnik Arheologii, Antropologii i Etnografii. 2015. No. 2 (29). Pp. 151-158. (In Russ.) карского). СПб.: Тип. Имп. акад. наук, 1872. $29 \mathrm{c.}$

Псянчин 2017 - Псянчин А. В., Алламуратова Л. Х. Дорога в традиционных представлениях башкир // Мир Центральной Азии - 4. Сб. науч. ст. / отв. ред. Е. В. Сундуева, науч. ред. Б. В. Базаров. Иркутск: Оттиск, 2017. С. 118-121.

Р-н 1832 - Р-н П. Сведения о башкирцах // Московский телеграф. Ч. 48. М., 1832. С. 259277.

Роднов 2002 - Роднов М. И. Крестьянство Уфимской губернии в начале XX века (1900-1917 гг.): социальная структура, социальные отношения. Уфа: ДизайнПолиграфСервис, 2002. 314 с.

Руденко 2006 - Руденко С. И. Башкиры: историко-этнографические очерки. Уфа: Китап, $2006.376 \mathrm{c}$.

Рычков 2002 - Рычков П. И. История Оренбургская по учреждению Оренбургской губернии. Уфа: Изд. АН РБ, 2002. 195 с.

Таиров 1995 - Таиров А. Д. Торговые коммуникации в западной части Урало-Иртышского междуречья. Препринт. Челябинск: ЧелГУ, $1995.43 \mathrm{c}$.

Татищев 1962 - Татищев В. Н. История Российская. Т. 1. М.; Л.: АН СССР, 1962. 500 с.

Толстой 1979 - Толстой Л. Н. Повести и рассказы. Уфа: Башк. кн. изд-во, 1979. 335 с.

Тулвинские татары 2004 - Тулвинские татары и башкиры: Этнографические очерки и тексты / под ред. A. B. Черных. Пермь: Перм. кн. изд-во, 2004. 455 с.

Филоненко 1914 - Филоненко В. И. Башкиры // Вестник Оренбургского учебного округа. Уфа, 1914. № 8. С. 297-308.

ФОЭ ИИЯЛ УФИЦ РАН — Фототека отдела этнологии ИИЯЛ УФИЦ РАН.

Хабибуллина 2009 - Хабибуллина 3. Р. Хадж мусульман Башкортостана: история и современные тенденции // Известия Самарского научного центра Российской академии наук. 2009. T. 11. № 6. С. 312-317.

Щепанская 2003 - Щепанская Т. Б. Культура дороги в русской мифоритуальной традиции ХІХ-XX вв. М.: Индрик, 2003. 527 с.

Akhundov M. D. Concepts of Space and Time: Origins, Evolution, Perspectives. Moscow: Nauka, 1982. 224 p. (In Russ.)

Allamuratova L. Kh. Preparing for a trip in the Bashkir traditional culture of travelling. 
Science Prospects. 2015. No. 5(68). Pp. 27-29. (In Russ.)

Aminev Z. G. Roads of the Southern Urals and their impact on Bashkir ethnogenesis. In: Ilimbetova A. F., Migranova E. V. (comps.), Yusupov R. M., Khisamitdinova F. G., Kulsharipov M. M. (eds.) Phenomenon of Eurasianism in Material and Spiritual Culture, Ethnology and Anthropology of the Bashkir People. Conference Proceedings (Ufa; May $27-$ 29, 2009). Ufa: Institute of History, Language and Literature (Ufa Scientific Center of RAS), 2009. Pp. 25-27.

Aznabaev B. A. Bashkir Society: $17^{\text {th }}$-First Third of the $18^{\text {th }}$ Century. Ufa: Bashkir State University, 2016. 370 p. (In Russ.)

Bayburin A. K. Dwelling in Rituals and Representations of East Slavs. Leningrad: Nauka, 1983. 188 p. (In Russ.)

Chernykh A. V. (ed.) Tulva Tatars and Bashkirs: Ethnographic Essays and Texts. Perm: Perm Book Publ., 2004. 455 p. (In Russ.)

Filonenko V.I. The Bashkirs. VestnikOrenburgskogo uchebnogo okruga. 1914. No. 8. Pp. 297-308. (In Russ.)

Gaisina F. F. Road-related beliefs and taboos of Bashkirs. In: Karimova R. N. (comp.), Khisamitdinova F. G. et al. (eds.) Ural-Altai: Through Centuries into the Future. Conference Proceedings (Ufa; March 25-27, 2010). Ufa: Institute of History, Language and Literature (Ufa Scientific Center of RAS), 2010. Vol. 1. Pp. 89-92. (In Bash.)

Garustovich G. N. A Trace of the Great Turmoil: $14^{\text {th }}$-Century (Archaeological) Site near BrikAlga. Ufa: Gilem, 2012. 222 p. (In Russ.)

Georgi J. G. Description of All Peoples Inhabiting the Russian State: Their Household Rituals, Practices, Clothes, Dwellings, Activities, Entertainments, Faiths and Other Memorable Phenomena. Part II. St. Petersburg: Imperial Academy of Sciences, 1799. 178 p. (In Russ.)

Golovnev A. V. Anthropology of Movement: Antiquities of North Eurasia. Yekaterinburg: Ural Branch of RAS; Volot, 2009. 496 p. (In Russ.)

Golovnev A. V. Conceptualization of mobility in anthropology and ethnography. Ural Historical Journal. 2018. No. 3 (60). Pp. 6-15. (In Russ.)

Ivanova G. V. Traditional road culture of the Karelians shown in the newspaper 'Olonetskie gubernskie vedomosti' (1838-1917). FinnoUgric World. 2017. No. 2. Pp. 72-84. (In Russ.)
Kazantsev N. Description of the Bashkirs. St. Petersburg: Obshchestvennaya Polza, 1866. 97 p. (In Russ.)

Khabibullina Z. R. Hajj of Bashkortostan Muslims: history and current trends. Izvestia of Samara Scientific Center of the Russian Academy of Sciences. 2009. Vol. 11. No. 6. Pp. 312-317. (In Russ.)

Korshunkov V. A. Russia's Road Tradition: Beliefs, Customs, Rites. Moscow: Forum, 2015. 240 p. (In Russ.)

Lepekhin I. I. 1770 Travel Notes of Ivan Lepekhin, Academician and Medical Doctor: Continuation. Part II. St. Petersburg: Imperial Academy of Sciences, 1802. 338 p. (In Russ.)

Matveev A. V. Population of the Middle Irtysh: Traditional Travel Culture, $19^{\text {th }}$ - First Third of the $20^{\text {th }}$ Century. Omsk: Nauka, 2012. 196 p. (In Russ.)

Migranova E. V. Bashkir Traditional Food System: A Historical-Ethnographic Study. Ufa: Kitap, 2016. 292 p. (In Russ.)

Migranova E. V. Survivals of traditional prohibitions in contemporary Bashkir society. The Problems of Oriental Studies. 2018. No. 4 (82). Pp. 30 37. (In Russ.)

Mullagulov M. G. Transport Means of the Bashkirs: $19^{\text {th }}-$ Early $20^{\text {th }}$ Century. Ufa: Bashkir Scientific Center (Ural Branch of RAS), 1992. 152 p. (In Russ.)

Nadrshina F. A. (comp.) Bashkir Folklore: Proverbs and Sayings. Ufa: Bashkir Book Publ., 1980. 472 p. (In Bash. and Russ.)

Nadrshina F. A. (comp.) Bashkir Tales and Legends. Ufa: Bashkir Book Publ., 1996. 204 p. (In Russ.)

Nazarov P. S. Bashkir ethnography revisited. Etnograficheskoe obozrenie. 1890. No. 1-2. Pp. 164-192. (In Russ.)

Pallas P. S. Travels through Different Provinces of the Russian Empire. Book I. Part 2. St. Petersburg: Imperial Academy of Sciences, 1786. 476 p. (In Russ.)

Pekarsky P. P. When and why were Ufa and Samara founded? (Historical inquiries of Academician Peter P. Pekarsky). SPb.: Tip. Imp. akad. nauk, $1872.29 \mathrm{~s}$.

Psyanchin A. V., Allamuratova L. Kh. The road in the Bashkir traditional conceptions. In: Sundueva E. V. (ed.) The World of Central Asia - 4. Collected Papers. Irkutsk: Ottisk, 2017. Pp. 118-121. (In Russ.)

R-n P. Data on Bashkirs. Moskovskiy telegraf. 1832. No. 48. Pp. 259-277. (In Russ.) 
Rodnov M. I. Peasants of Ufa Governorate in the Early $20^{\text {th }}$ Century (1900-1917): Social Structure, Social Relations. Ufa: Dizayn Poligraf Servis, 2002. 314 p. (In Russ.)

Rudenko S. I. The Bashkirs: Historical-Ethnographic Essays. Ufa: Kitap, 2006. 376 p. (In Russ.)

Rychkov P. I. A History of Orenburg: Since the Establishment of Orenburg Governorate. Ufa: Bashkortostan Academy of Sciences, 2002. 195 p. (In Russ.)

Sagitov M. M. (comp.) Bashkir Folklore: Epic. Ufa: Bashkir Book Publ., 1987. 544 p. (In Bash. and Russ.)

Shchepanskaya T. B. Road Culture in the Russian Mythoritual Tradition: $19^{\text {th }}-20^{\text {th }}$ Centuries. Moscow: Indrik, 2003. 527 p. (In Russ.)

Tairov A. D. Trade Communications in the Western Ural-Irtysh Region. Preprint. Chelyabinsk:
Chelyabinsk State University, 1995. 43 p. (In Russ.)

Tatishchev V. N. Russian History. Vol. 1. Moscow; Leningrad: USSR Academy of Sciences, 1962. 500 p. (In Russ.)

Tolstoy L. N. Novels and Short Stories. Ufa: Bashkir Book Publ., 1979. 335 p. (In Russ.)

Ufa Federal Research Centre of the RAS; Institute of History, Language and Literature; Photograph Collection.

Vasilyev M. I. Russian Ground Communications and Sliding Vehicles, $10^{\text {th }}-$ Early $20^{\text {th }}$ Centuries: Key Development Trends. Dr.Sc. (history) thesis abstract. St. Petersburg, 2009. 48 p. (In Russ.)

Yusupov R. M. (ed.) The Bashkirs: Ethnic History and Traditional Culture. Ufa: Bashkirskaya Entsiklopediya, 2002. 248 p. (In Russ.) 